\title{
Revisitando a história da imigração e da colonização no Paraná provincial.
}

\author{
Revisiting the history of immigration and colonization in provincial \\ Paraná
}

Joseli Maria Nunes Mendonça*

RESUMO

Este artigo objetiva revisitar dois temas consagrados na historiografia sobre o Paraná - a colonização e a imigração. Os estudos que se dedicaram a tais temáticas tenderam, no geral, a enfatizar a estreita relação entre estas duas experiências históricas, registrando que, no Paraná, a colonização se efetivou por meio da imigração e esta foi implementada no sentido de colonizar a região, o que se fez por meio de pequenos proprietários de origem estrangeira (os colonos) que se dedicavam à agricultura de abastecimento. Utilizando fontes também já bastante exploradas por pesquisadores da história regional relatórios de presidentes de província e legislação - mas priorizando um período pouco estudado - os anos 1850 e 1860 - e elencando questões relacionadas à definição de políticas públicas para a província recém-constituída, a pesquisa evidenciou que a proletarização foi uma experiência comum para os imigrantes naquele período e que os chamados "nacionais" foram agentes fundamentais nos projetos de colonização então implementados. O artigo, portanto, problematiza a sinonímia constituída pela historiografia entre os termos imigração e colonização, evidenciando um contexto de rupturas, indeterminações e expectativas múltiplas.

Palavras-chave: História, Paraná, Imigração, Colonização. Nacional.

\section{ABSTRACT}

This article revisits two established themes in the historiography of Paraná: immigration and colonization. Studies dedicated to these themes had a general tendency to focus on the narrow relationship between these two historical experiences, appointing that, in Paraná, colonization was made effective by means of small land owners of foreign origin (the colonials) who farmed their land for general supply agriculture.

"Doutora em História pela Unicamp. Professora do Departamento de História da Universidade Federal do Paraná. 
Using sources that have also been largely explored by researchers of regional history - reports from province presidents and legislation - but prioritizing a less-studied period - the years 1850 and $1860-$ and presenting questions related to the definition of public politics for the recently-constituted province, the research made evident that the proletarianization was a common experience for the immigrants in that period and that the so-called "nationals" were fundamental agents in the colonization projects then being implemented. The article, therefore, shows the problems of the synonymy constituted by the historiography between the words immigration and colonization, giving evidence to a context of ruptures, indeterminations and multiple expectations.

Keyword: History. Paraná, Immigration, Colonization National.

\section{Imigração e colonização na historiografia sobre o Paraná}

Tendo sido experiência crucial no Paraná do século XIX e primeiras décadas do XX, a imigração é também tema central na constituição de memórias e identidades locais e é objeto privilegiado de pesquisadores que se dedicaram à história regional.

Uma das vertentes de abordagem a enfatizar a importância da imigração para a história do Paraná estabeleceu-se ainda no final do século XIX e nas primeiras décadas republicanas, quando o fluxo imigratório era bastante intenso. Por meio do Paranismo - movimento de cunho intelectual e político - uma identidade local fortemente associada à imigração europeia começou a ser forjada. (PEREIRA, 1997; OLIVEIRA, 2009; BEGA, 2013). Um dos autores mais significativos neste contexto foi Romário Martins, cuja produção intelectual, desde 1899, esteve associada à constituição de uma narrativa histórica na qual a presença de imigrantes europeus se destacava como elemento distintivo da identidade paranaense. (MARTINS, 1995). Em 1940, estimulado pela divulgação dos dados do censo demográfico então realizado, Romário Martins publicou o estudo Quantos somos, quem somos. Na obra, Martins procurava tratar a população do Paraná em perspectiva quantitativa e, sobretudo, caracterizá-la em relação à sua origem étnica, atentando para a história que envolveu a entrada de contingentes populacionais europeus na região. (MARTINS, 1941).

A ênfase na importância da imigração para a constituição populacional no Paraná também caracterizou a obra de outro importante intelectual que se dedicou à história regional: Wilson Martins. Na produção deste autor, como também na de Romário Martins, se destaca o objetivo contundente de definir a especificidade da composição populacional do Paraná e das relações interétnicas ali estabelecidas, distinguindo-as daquelas estabelecidas em outras regiões do país. Quando publicou Um Brasil diferente, Wilson Martins explicitou o diálogo que pretendera realizar com Gilberto Freyre a respeito da interpretação que este havia estabelecido sobre as relações 
sócio-raciais, quando da publicação de Casa Grande \& Senzala, em 1933. Com o livro publicado em 1955, Wilson Martins pretendeu, segundo anunciava o próprio subtítulo, estudar os fenômenos de aculturação no Paraná que, como dizia, decorriam do contato estabelecido entre estrangeiros de diversas origens europeias. Para Martins, a formação social do Paraná não havia sido resultado da convivência entre índios, portugueses e negros, como ocorrera no ambiente social estudado por Gilberto Freyre. Isso porque, explicava Martins, a história do Paraná fora absolutamente diversa da história do restante do país; não porque ali a assimilação de elementos socialmente diversos não tivesse ocorrido, mas porque tal assimilação envolvera grupos distintos daqueles que interagiram em outras regiões, reunindo elementos de origem europeia: poloneses, italianos, austríacos, alemães, russos, ucranianos. Assim, embora a assimilação fosse elemento comum em relação a outros locais - como o nordeste açucareiro estudado por Freyre -, a imigração havia sido elemento de distinção de um processo histórico do qual resultara a formação social paranaense. (MARTINS, 1989).

Já no final da década de 1950, um grupo de pesquisadores vinculados à Universidade Federal do Paraná, a partir de uma revisão crítica da produção historiográfica sobre a região, produziu uma extensa agenda de pesquisas demográficas, buscando coligir séries documentais que as viabilizassem ${ }^{1}$. Em 1974, em um colóquio organizado em comemoração ao primeiro centenário de Romário Martins, Altiva Balhana - que fez parte da equipe que elaborou a agenda de pesquisa aqui referida - explicitou que uma das vertentes de investigação então proposta dizia respeito justamente "às transformações ocorridas com a entrada de novos contingentes étnicos que alteraram o quadro demográfico do Paraná, e compreend[ia] o estudo dos primeiros grupos de alemães, poloneses, italianos, ucranianos, e outros grupos de imigrantes estabelecidos no território paranaense" (BALHANA, 2002, p. 410). No final dos anos 1960 um quadro bastante amplo de pesquisas já havia se constituído e, a partir de então, consolidaram-se vários estudos sobre a imigração e sobre os grupos étnicos que configuraram a população paranaense. Problematizando sobretudo a preservação de elementos culturais dos vários grupos imigratórios e as dinâmicas grupais de autopreservação, tais pesquisas tenderam a destacar as experiências e relações estabelecidas no interior de um grupo de origem específica - os ucranianos, os poloneses, os alemães. (ANDREAZZA, 1999; BOSCHILIA, 2004; NADALIN, 2000; WACHOWICZ, 1974; WACHOWICZ, 1977).

Não obstante todas as inflexões de abordagem ${ }^{2}$ e de referenciais teórico-metodológicos, algumas características da produção anteriormente realizada se mantiveram nesta profícua produção empreendida a partir da década de 1960. Uma delas diz respeito à forma de problematizar a inserção dos imigrantes na formação social paranaense. Como as indagações que orientaram as pesquisas visavam sobretudo entender as dinâmicas estabelecidas em um grupo étnico específico,

\footnotetext{
1 Tal agenda se constituiu a partir da leitura e crítica que fizeram os professores do Departamento de História sobre a produção de Romário Martins, como evidencia a Ata da Reunião do Departamento de História da Faculdade de Filosofia da Universidade Federal do Paraná Realizada em 2 de Dezembro de 1964 [Registrando sua Constituição em Princípios de Maio de 1959].

${ }^{2} \mathrm{O}$ que não significa que as características anteriormente definidas não tenham persistido na produção de intelectuais em período posterior, como é o caso da realizada Bento Munhoz da Rocha Neto que, na década de 1960, identificava nas raízes europeias o elemento distintivo da história do Paraná e do sul em geral. Sobre o tema: Zwako (2009).
} 
se privilegiou o estudo de núcleos coloniais em que se podia encontrar um grande número de imigrados de uma mesma etnia. Assim, os sujeitos históricos estudados foram especialmente aqueles imigrantes que se estabeleceram como pequenos proprietários, atuando, portanto, como colonizadores. Desta maneira, imigração e colonização, na História do Paraná, passaram a constituir uma relação de sinonímia. Ali, como nos outros estados do Sul, o termo "colono" é, até hoje, utilizado para referir o imigrante e seus descendentes, constituídos pequenos proprietários; no sudeste - especialmente em São Paulo - o termo serve para designar alguém que se emprega em uma propriedade agrícola. Sentidos distintos em razão de processos históricos que, no século XIX, teriam sido distintos em cada uma das regiões e que, portanto, teriam definido especificidades às áreas meridionais.

Em decorrência do tipo de problema que orientava as pesquisas, os estudos tenderam a privilegiar o período posterior a 1870 - quando o poder público provincial, em especial a partir da gestão do presidente Lamenha Lins, passou a estimular a formação de núcleos coloniais em áreas próximas aos centros urbanos, sobretudo a capital da província. Nestas áreas os colonos produziam gêneros de abastecimento, que comercializavam na cidade ${ }^{3}$. No mesmo período, principalmente na década de 1890, as colônias passaram a agregar imigrantes de uma mesma etnia, o que propiciava uma situação empírica favorável à caracterização das interações entre eles na situação colonial, foco de interesse dos pesquisadores.

Da compreensão de que a imigração na província e posteriormente no estado do Paraná esteve voltada para o povoamento e a produção agrícola de gêneros alimentícios decorre uma abordagem que enfatiza as continuidades entre a história da imigração na região e os princípios firmados inicialmente para promoção da imigração na América portuguesa e no Brasil recémindependente. Neste sentido, toma-se como marco a publicação da Carta de Régia de 1808 que, em geral se considera, teria inaugurado e firmado os princípios da política de povoamento da América portuguesa e, posteriormente, do Brasil. Como indicaram Balhana (2002, p. 362) e Lazzari (1980, p. 31), a Carta inovava ao derrogar as restrições aos que, não sendo súditos do Império português, adentrassem em território americano. Assim estipulava a ordem expedida por D. João à Mesa do Desembargo do Paço, para que esta a executasse:

Sendo conveniente ao meu real serviço e ao bem público, aumentar a lavoura e a população, que se acha muito diminuta neste Estado; e por outros motivos que me foram presentes: hei por bem, que aos estrangeiros residentes no Brasil se possam conceder datas de terras por sesmarias pela mesma forma, com que segundo as minhas reais ordens se concedem aos meus vassalos, sem embargo de quaisquer leis ou disposições em contrário. (BRASIL, 1891, p. 166).

${ }^{3}$ Destacam-se, em relação à temática da produção agrícola voltada ao abastecimento, os estudos de Carlos Antunes, destacadamente, Santos (1995). 
Esta nova política de ocupação do território, desta forma, estendia aos estrangeiros a possibilidade de obter sesmarias por concessão do Príncipe Regente, que, então, governava o Império português. A partir daí, segundo a interpretação corrente, instituiu-se na América portuguesa e, posteriormente, no Brasil, uma clara política de incentivo à imigração orientada pelo objetivo de ocupar o território, desenvolver a agricultura e incrementar a produção de gêneros de abastecimento. Assim, colonização e imigração passaram a ser ações estreitamente relacionadas e orientaram a criação de diversos núcleos: durante o Governo Joanino, Nova Friburgo, formada por migrantes suíços na Serra Fluminense; no Primeiro Reinado, em 1828, São Leopoldo, Três Forquilhas e Torres, no Rio Grande do Sul, com colonos alemães que, em 1829, também foram fixados nos núcleos de Santo Amaro e em Rio Negro, que à época fazia parte de São Paulo e, posteriormente, foi integrada à província do Paraná; São Pedro de Alcântara e Itajaí, em Santa Catarina (MACHADO, 1999, p.20; COSTA, 1989, p. 99; BALHANA, 2002, p. 362).

Esses núcleos, como considerou Emília Viotti da Costa (1989, p. 99), tinham objetivos demográficos, orientados pela necessidade de povoar o território. Também Balhana (2002, p.362), da mesma forma, observou que a política de imigração estava, no Governo Joanino e no Primeiro Reinado, orientada para preencher "vazios demográficos".

A partir das décadas de 1840-1850, com a expansão da cultura cafeeira no centro-sul e a restrição da reprodução da mão de obra de escravos por meio do tráfico atlântico, novas demandas passam a orientar a imigração. Além de serem requisitados para ocupação territorial e para produção de gêneros em pequenas propriedades - como ocorria nas áreas meridionais -, os imigrantes passam a ser demandados também para trabalhar nas grandes fazendas produtoras de café, sobretudo na província de São Paulo. Constituem-se, assim, como indicou Balhana, "duas orientações e duas práticas imigratórias no Brasil”. Uma delas, em consonância com os preceitos inicialmente estabelecidos, visava à formação de núcleos coloniais; outra tinha em vista a obtenção de trabalhadores agrícolas para área cafeicultora paulista. (BALHANA, 2002, p. 365). A própria legislação imperial, como observou lotti, expressaria tal transformação:

Basicamente até 1840, a política imigratória brasileira estava voltada para a criação de núcleos coloniais baseados na pequena propriedade. A partir desta data, intensifica-se o conflito de pressões entre, de um lado, os grupos representativos do pensamento democrático, partidários da instituição de 'colônias' de pequenos e médios proprietários, e, de outro lado, a camada dos latifundiários do café que impunham, cada vez mais fortemente, a solução ditada por seus interesses: a política de 'braços livres', isto é, a importação de trabalhadores estrangeiros para a substituição, em suas fazendas, do decadente e já improdutivo trabalho escravo (IOTTI, 2003, p. 23-24). 
Assim, configura-se a percepção de que as duas políticas imigratórias coexistiram, mas uma delas esteve restrita às regiões meridionais e outra à área da grande produção cafeeira; uma, teria gerado uma sociedade de pequenos proprietários; outra, voltada aos interesses dos latifundiários, proletarizou os imigrantes, transformados em substitutos dos escravos nas lides da grande lavoura de exportação.

Não obstante as novas demandas que passaram a orientar a política imperial para introdução de imigrantes, no Paraná, após 1853, segundo Balhana, Machado e Westphalen, teria prevalecido a orientação inicialmente definida, qual seja, a de se introduzir lavradores que produzissem gêneros de abastecimento e se fixassem em pequenas propriedades. Continuava vigendo, nesta região, "o princípio de que os cofres públicos deveriam apenas financiar a imigração destinada à agricultura". Segundo os autores, as autoridades provinciais defendiam que os imigrantes deveriam receber pequenos lotes de terra, por venda a preços módicos ou por aforamento. A política imigratória na província, assim, "visava o progresso agrário, pela constituição de pequenas propriedades destinadas à produção de gêneros de abastecimento" (BALHANA; MACHADO; WESTPHALEN, 1969, p. 161-162).

Também enfatizando a relação entre imigrante e pequena propriedade, Brasil Pinheiro Machado considerou que o sistema de colonização desenvolvido no Paraná teve por objetivo estabelecer uma civilização camponesa à maneira da Europa, onde pequenas propriedades agrupadas ao redor de uma aldeia visavam o abastecimento das cidades (MACHADO, 1968). Assim, nas regiões meridionais de São Paulo e depois na província do Paraná, mesmo a partir da década de 1840 - quando foram incorporadas novas demandas provenientes das áreas de cafeicultura - a política imigratória teria seguido coerente com o antigo princípio que havia sido inaugurado por D. João: promover a imigração para povoar o território, incrementar a produção agrícola e criar uma classe de pequenos proprietários. No Paraná, ao contrário do que ocorrera no centro-sul cafeeiro, os colonos eram imigrantes que se procurava fixar na terra, para povoá-la e para nela produzirem.

Uma análise que priorize outras questões - a definição de políticas governamentais voltadas à colonização da província - e que se detenha sobre outro período - as décadas anteriores a 1870 talvez possa evidenciar outras experiências vivenciadas pelos imigrantes e descortinar um contexto de rupturas, indeterminações e expectativas múltiplas, por vezes conflitantes. Este é o percurso que seguiremos a seguir. 


\section{Imigrantes para quê?}

A primeira lei referente à imigração constituída após a criação da província do Paraná foi aprovada em 1855, e determinava que o governo estava

autorizado a promover a emigração [sic] de estrangeiros para esta província, empregando neste sentido os meios que julgar mais convenientes, e preferindo sempre atrair os colonos e demais estrangeiros que já se acharem em qualquer das províncias do Brasil (PARANÁ, 1912, p. 16).

A mesma lei também estabelecia que fossem disponibilizados ao governo dez contos de réis para cobrir despesas de passagem e de alimentação dos estrangeiros introduzidos na província. $O$ artigo $3^{\circ}$ acrescentava que

Os colonos serão, por ora, principalmente destinados ao serviço das estradas da província, podendo o governo pagar, sem indenização alguma, a metade da passagem àqueles que nelas se empregarem por espaço de cinco anos. (PARANÁ, 1912, p. 16).

Os que quisessem se dedicar à agricultura e que não tivessem meios de fazer isso por sua conta, definia a lei, deveriam "ser distribuídos pelos lavradores, principalmente pelos de café, chá e trigo". Estes lavradores deveriam ressarcir "as despesas que com eles houver feito o governo", em prestações pagas "dentro de três anos e sem juro algum". (PARANÁ, 1912, p. 16).

A lei no 29 de 1855 não teve muito efeito. Nem chegou a ser elaborado o regulamento previsto no seu artigo $7^{\circ}$. Algumas observações do presidente da província, feitas pouco depois de a lei ter entrado em vigência, evidenciam possíveis razões para a inocuidade dela. No relatório que enviou à Assembleia provincial em 1856, aquela autoridade registrou:

Entendeu a assembleia provincial dever autorizar a presidência a despender anualmente a quantia de 10:000U000 rs., para promover a emigração [sic] de estrangeiros para esta província. Em execução da lei n. 29 de 21 de março 
de 1855, mandei, por edital de 11 de dezembro, convidar aqueles que pretendessem contratar colonos ou trabalhadores estrangeiros a fazerem as suas declarações, na forma do aviso do ministério do império n. 12 de 3 de outubro antecedente, indicando o número e nacionalidade dos colonos que se propusessem a contratar, as condições principais do contrato, que deve ligar reciprocamente o empresário e os colonos, qual o agente na Europa encarregado da comissão, e contendo finalmente todos os esclarecimentos precisos, a fim de que, por intermédio do governo imperial, se promovesse a realização dos ditos contratos (PARANÁ, 1856b, p. 40).

De fato, a lei orçamentária de 1856 estabelecia que enquanto o governo da província não dispusesse das terras para alocar imigrantes estes deveriam ser "distribuídos pelos estabelecimentos industriais" existentes na província (PARANÁ, 1912, p. 33-34). A mesma lei autorizava o governo a contratar com indivíduos ou empresas que quisessem introduzir imigrantes na província e os isentava de pagarem taxas de barreiras (espécie de pedágios cobrados em alguns pontos das estradas, calculado sobre o passageiro e sobre a bagagem). A lei estipulava, ainda, que o governo deveria inspecionar com rigor os contratos feitos entre empregadores e colonos, fiscalizando os valores dos salários pagos, as condições de vestuário dos colonos, exercendo, enfim, "constante vigilância para que os contratos [fossem] rigorosamente cumpridos". (art. $3^{\circ}$ ). Previa também que os empregadores não podiam cobrar dos colonos "retribuição alguma, além do preço da passagem", sobre a qual só poderiam incidir os juros estipulados legalmente. (o "prêmio legal") (artigos $4^{\circ}$ e $\left.5^{\circ}\right)$.

Apesar dos esforços empreendidos no sentido de dar execução à lei, como relatou o Presidente da província, o prazo de dois meses marcado para a apresentação das propostas "extinguiu-se, sem que um só empresário houvesse aparecido". Assim, observou ele, ou por ter sido impossível "encontrar proprietários habilitados para receber, por salário ou parceria, famílias de colonos"; ou "porque a província não [tinha] terras devolutas, onde as receba", a lei não podia ser executada, pelo menos não em relação às disposições referentes ao emprego de imigrantes colonos com proprietários agrícolas estabelecidos (PARANÁ, 1856b, p. 40).

A outra possibilidade colocada pela lei - o emprego de imigrantes nas obras públicas - não foi comentada pelo presidente da Província no ano de 1855. Entretanto, pode ser que esta fosse uma alternativa pouco viável, em razão da incipiência da organização administrativa da província recémemancipada. Provavelmente o emprego de colonos em obras públicas se viabilizasse se conjugado com a fixação deles em terras devolutas demarcadas pelo governo geral para este fim. É o que sugere o pedido feito pelo presidente ao Ministério do Império, para "concessão de uma porção de terreno entre a capital da província e a vila de Antonina", lugar, segundo ele, "mui apropriado à colonização" não só porque reunia "salubridade e fertilidade", mas pela feliz "circunstância de se 
achar vizinho à estrada da Graciosa, onde os colonos encontrarão trabalho remunerado" (PARANÁ, 1856b, p. 44). ${ }^{4}$

Com efeito, o emprego de imigrantes em obras públicas era um aspecto importante das políticas de imigração da província no período subsequente à emancipação administrativa. Por anos, os presidentes da província relataram as dificuldades para realização de tais obras, sobretudo as que visavam à construção de estradas e pontes. Uma das dificuldades apontadas para a realização destes empreendimentos dizia respeito exatamente à escassez de trabalhadores. No Relatório de 1856, por exemplo, o presidente da província, referindo-se às obras de melhoramento e manutenção da Estrada da Graciosa, que ligava Curitiba ao litoral, informava que "a falta de jornaleiros" era "o principal embaraço" para que os trabalhos não avançassem (PARANÁ, 1856c, p 3). Um ano antes, Zacarias de Gois e Vanconcelos já havia comentado, neste mesmo sentido:

A escassez de trabalhadores para o serviço das estradas, mesmo para o daquela (Graciosa) que considera-se necessidade vital da província, a repugnância que mostram a esse serviço os poucos sujeitos capazes de nela empregar-se, são conhecidas de todos: se a polícia não interviesse, constrangendo-os a irem, por escala, trabalhar, mediante os salários convenientes, não haveria no mês uma semana de trabalho" (PARANÁ, 1855, p. 31).

Explicitando a utilização de trabalho compulsório para a construção da estrada, adiante complementava: "Não seria, pois, de utilidade pública aliciar, ainda com algum sacrifício, a introdução de certo número de colonos para trabalhar em as nossas primeiras estradas [...]?" (PARANÁ, 1855, p. 31).

Assim, é possível considerar que, dada a inexistência de terrenos devolutos concedidos à colonização pelo governo geral, dada a necessidade de trabalhadores para obras necessárias ao desenvolvimento e integração da província, o emprego de colonos em empreendimentos públicos era um elemento central nas políticas provinciais relativas à imigração neste período subsequente à criação do Paraná. Mesmo em períodos anteriores, o emprego de colonos na abertura ou manutenção de estradas não havia sido incomum nas regiões meridionais. Em 1829, vários integrantes das 51 famílias alemãs que foram fixadas em Rio Negro e às quais se atribui o início da colonização germânica na região foram para lá levados para trabalhar em uma importante obra pública. Transferidos de Santo Amaro para o pequeno povoado por José da Silva Machado posteriormente Barão de Antonina - os "imigrantes fundadores" foram ali estabelecidos para

${ }^{4} \mathrm{O}$ projeto não foi em frente, pois o Ministério, para a concessão do terreno, impôs a condição de que houvesse oito léguas quadradas de terrenos devolutos na área, o que não era o caso. É possível que este projeto do governo provincial tenha se realizado, em outro local, posteriormente, quando da fundação da colônia de Assungui. 
trabalhar no melhoramento da Estrada da Mata, que ligava Viamão a Sorocaba e na qual eram conduzidas as tropas de mulas, essenciais para a economia de toda a região sul e centro-sul. (BORGES, 2014, p. 80-81; GOULART FILHO, 2012, p. 8).

Por toda a década de 1850, os presidentes de província relataram os esforços feitos para engajar imigrantes para o trabalho de construção de estradas, tarefa para a qual a carência de trabalhadores era um problema crônico. Em 1857, Antonio Carvalhaes, que exercia a presidência da província, dizia de seu empenho em prover as obras da estrada da Graciosa de mão de obra:

\begin{abstract}
Vendo que tornava-se progressivamente mais escasso o número dos trabalhadores da Graciosa, enviei à colônia D. Francisca o alemão Frederico Dauch, incumbido de contratar 40 colonos, próprios para o serviço daquela estrada, mediante os salários que atualmente se pagam aos jornaleiros que nela servem". (PARANÁ, 1858, p. 98).
\end{abstract}

Em 1858 o presidente Liberato de Matos mandou contratar 50 portugueses que deveriam se empregar na construção de estradas da Graciosa. Somente 30 foram engajados na obra (PARANÁ, 1858b). ${ }^{5}$

Também em períodos posteriores, na década de 1860 e 1870, o trabalho de colonos imigrantes nas obras públicas não era nada desprezível. Os imigrantes da colônia de Assungui, criada em 1860, eram tão importantes para viabilizar os empreendimentos de construção e manutenção de obras públicas quanto era importante para sua sobrevivência a remuneração que recebiam por tais tarefas $^{6}$. Quando visitou a colônia em 1874, o cônsul inglês nomeado para fiscalizar a condição dos súditos britânicos no núcleo colonial registrou que aos colonos "esfomeados" não restava outra esperança que a de conseguir trabalho remunerado nas estradas (HUNT, 1998, p 28). ${ }^{7}$. A importância do engajamento daqueles colonos nas obras do governo provincial é evidenciada pela constância com que eles relataram ao cônsul inglês a dependência que tinham em relação à remuneração dessas tarefas, os atrasos nos pagamentos, as péssimas condições a que eram submetidos nestas atividades. Assim, ainda fosse objetivo do governo criar um núcleo no qual se constituíssem pequenos proprietários que se dedicassem à agricultura de abastecimento, a destinação de mão de obra para as obras públicas estava também na mira das autoridades e a experiência de proletarização foi efetiva e premente para os estrangeiros que se instalaram em

\footnotetext{
${ }^{5}$ PARANÁ. Relatório do presidente da província do Paraná, Francisco Liberato de Mattos, na abertura da Assembleia Legislativa Provincial em 7 de janeiro de 1858. Curitiba, Typ. Paranaense de C. Martins Lopes, 1858.

${ }^{6}$ A importância do trabalho que os imigrantes realizavam nas obras públicas no Rio Grande do Sul - tanto para seu sustento como para viabilidade do projeto colonial - (MACHADO, 1999, p. 84 e segs). Também em Santa Catarina, especificamente na colônia Blumenau, era imprescindível a vários imigrantes a remuneração que recebiam por trabalhos que realizavam nas obras coloniais ou pela prestação de serviços a outros proprietários (NICOCELI, 2014, p. 90 e segs.).

${ }^{7}$ Sobre Assunguy e a condição dos colonos, cfe. também: Lamb (1994), Pereira (1998, p. 1-15), Nishikawa (2007).
} 
Assungui. Dada a intensidade do êxodo de imigrantes da colônia - a que me referirei a seguir pode-se mesmo considerar que tenha sido a experiência predominante entre esses indivíduos que, vindos de várias regiões da Europa foram conduzidos a Assungui nas décadas de 1860 e 1870 . Magnus R. M. Pereira chamou a atenção para a condição híbrida que caracterizou as atividades produtivas dos imigrantes que deixaram os núcleos coloniais e se estabeleceram em Curitiba: eram empregados domésticos, operários e pequenos granjeiros. Na periferia da cidade, conforme considerou o historiador, "viviam famílias sobre as quais é difícil saber se complementavam seus salários com uma produção agrícola, ou se complementavam a renda obtida na agricultura com os salários de alguns de seus membros, empregados como operários ou criados urbanos." (PEREIRA, 1998, p. 12).

Embora, em geral, a historiografia regional considere que o emprego de imigrantes em obras públicas tenha sido uma característica do movimento imigratório mais tardio ${ }^{8}$, sobretudo o realizado na década de 1880, o que procurei argumentar até aqui é que esta destinação estava na base da definição das políticas que inauguraram a introdução de imigrantes na província. Ainda que o incentivo à produção de abastecimento por pequenos proprietários fosse uma meta importante, o emprego de imigrantes em obras públicas e, portanto, sua proletarização, foi não só objetivado como praticado amplamente no Paraná desde a década de 1850.

\section{Colonos Nacionais}

Escrevendo na década de 1980 , Petrone $(1982$, p. 18) considerou que a introdução de imigrantes no Paraná do século XIX possibilitou a formação de uma "numerosa população de pequenos proprietários solidamente radicada na terra".

Esta, de fato, foi uma das expectativas expressas por homens públicos que estiveram envolvidos nos projetos de colonização relativos à região meridional de São Paulo e, posteriormente, à província do Paraná. Na perspectiva de muitos deles, imigrantes - sobretudo europeus - seriam os sujeitos mais adequados para colonizar o território, pois se dedicariam preferencialmente à produção de gêneros de abastecimento (PARANÁ, 1858b, p. 35). Segundo o Presidente da Província em 1868, a "imigração de colonos morigerados e laboriosos", que, fossem "conhecedores dos processos mais acabados, e habituados ao uso de instrumentos mais

\footnotetext{
${ }^{8}$ Para Balhana, Machado e Westphalen (1969, p. 180-181), no período pós 1880 findou "uma fase de programação colonizadora no Paraná, com a extinção do sistema de colonização oficial, com colônias mantidas sob a tutela do governo, e o início de outra etapa com motivações diferentes e com menor participação oficial". Na "nova conjuntura, inaugurada pela realização de grandes obras públicas, como a construção de estradas de ferro e de linhas telegráficas, iniciadas a partir de 1880, abriram-se novas perspectivas para o problema da introdução de imigrantes, oferecendo oportunidades de trabalho para grandes massas de trabalhadores."
} 
vantajosos ao maneio de cultura das terras" poderia corrigir os problemas de abastecimento que vivia a província. (PARANÁ, 1868).

Segundo considerou Petrone (1982, p. 18), a instabilidade que predominava em outras atividades (na mineração, nas fazendas pecuaristas, no tropeirismo e extração madeireira), teria sido suplantada com a criação de núcleos coloniais, nos quais os europeus se instalaram como pequenos proprietários rurais.

Estas considerações, conquanto possam caracterizar o processo de colonização ocorrido a partir dos anos 1870, não condizem com a experiência da maior parte dos imigrantes instalados nas colônias da região nos primeiros três quartéis do século XIX. Estudos mais recentes vêm demonstrando que neste período poucos estrangeiros se tornaram proprietários nos locais em que foram originalmente alocados e, antes, tenderam, em sua imensa maioria, a abandoná-los (LAMB, 1994; PEREIRA, 1996; NISHIKAWA, 2007; DYSARZ, 2011).

Uma das primeiras colônias constituídas na região meridional de São Paulo - quando ainda não havia sido criada a província do Paraná - foi denominada Thereza, fundada em 1847, por JeanMaurice Faivre, nas margens do Rio Ivaí, onde atualmente está localizado o município de Cândido de Abreu. Ali, o médico francês alocou os 60 franceses e 4 belgas que com ele haviam partido do porto de Antuérpia em dezembro de 1846 (BALHANA; MACHADO; WESTPHALEN, 1969, p. 158; LEANDRO, 1996; FERNANDES, 2006, p. 66, 78). Um ano após o estabelecimento do núcleo, já era marcante o êxodo de estrangeiros, constrangidos pelas extremas dificuldades que encontraram para se fixarem na terra e nela produzirem. Ataques desferidos por indígenas que habitavam a região, doenças, dificuldades de locomoção, o árduo trabalho de derrubar matas para abrir terrenos às plantações foram alguns dos problemas que levavam os primeiros colonos estrangeiros e os que foram introduzidos no núcleo posteriormente a abandonarem o local. Em 1856, o presidente da província, referindo-se a uma segunda leva imigrantes introduzidos por Faivre, dissera que dos "79 franceses que trouxe, quase todos se retiraram, desanimados pelas dificuldades que encontraram naquele sertão" (PARANÁ, 1856b, p. 44).

O êxodo de estrangeiros era grande, mas era da mesma forma significativo o número de brasileiros que se fixavam na colônia. Como informou o presidente da província, "à proporção que os colonos daquela nacionalidade [franceses] abandonavam o estabelecimento, crescia o número dos povoadores brasileiros, pela agregação de famílias dos municípios de Castro e Guarapuava" (PARANÁ, 1856b, p. 44). Segundo a autoridade provincial, a colônia tinha, naquele ano, uma população de 190 indivíduos, dentre os quais 171 eram brasileiros e somente 19 eram franceses. No relatório que havia feito em 1854, outro presidente do Paraná já havia notificado aos parlamentares da província que "na colônia Thereza há tantos filhos do país, que a denomina seu fundador colônia Franco-Brasileira” (PARANÁ, 1854, p. 69).

Esta maneira com que Faivre denominava o núcleo talvez não fosse fortuita. Desde o início de seu empreendimento, ele contara com auxílios pecuniários do governo imperial. Um deles, foi feito 
pela Imperatriz Thereza Cristina, que o presenteou com 6 contos de réis, retirados de suas provisões $^{9}$. A gratidão de Faivre foi expressa na homenagem que fez ao nomear a colônia com o nome da benemérita. Posteriormente, o governo imperial concedeu três empréstimos ao colonizador. O primeiro, feito em 1847, estava condicionado à quantidade de imigrantes introduzidos por Faivre, que recebeu, então, 3 contos e 200 mil réis que correspondiam a 50 mil réis por cada um dos 64 estrangeiros que havia alocado na colônia naquele ano. O empréstimo deveria ser pago em três prestações, a primeira vencendo dois anos após a data da concessão. O governo reservava-se o direito de fiscalizar a colônia, para verificar se os imigrantes achavam-se efetivamente ali estabelecidos. O êxodo dos colonos estrangeiros, assim, representava um duplo problema para Faivre: privava a colônia de produtores e, ainda, não preenchia a condição pela qual o empréstimo Ihe fora concedido pelo governo.

Esta situação tornou-se ainda mais problemática, pois o prazo para o pagamento da primeira parcela do empréstimo não fora cumprido e Faivre precisou negociar a dívida. A negociação parece não ter sido desfavorável ao colonizador: em 1850 ele recebeu do governo imperial 16 contos de réis, dos quais foram abatidos os 3 contos e 200 que devia. Em 1854 um novo empréstimo o socorreu, desta feita totalizando 18 contos de réis (FERNANDES, 2006, p. 140-142).

O fato de colonos brasileiros terem ocupado os lugares deixados vazios pelos imigrantes cuja alocação condicionara a concessão do primeiro empréstimo possivelmente tenha constituído importante argumento na negociação de Faivre com o governo, afinal, a colônia não estava desabitada, ainda que os habitantes não fossem os inicialmente pretendidos. Ao menos é o que sugerem algumas considerações feitas em 1854 por Zacarias de Gois e Vasconcelos, o primeiro presidente da província então recém-criada. Naquela oportunidade, para demonstrar que a colônia Thereza vinha sendo bem sucedida, Gois e Vasconcelos retomava uma experiência anterior, realizada em região próxima. Em 1828, dizia ele, "o barão de Antonina, cujo nome anda associado às ideias de mor utilidade para esta província, dirigiu o estabelecimento de uma colônia de alemães no Rio Negro" (PARANÁ, 1854, p. 69). Embora os alemães tivessem dispersado, dizia o presidente, a importância da ação colonizadora do barão não diminuíra, pois o núcleo não desapareceu, tendo sido ocupado por uma significativa população nacional que, naquele ano, segundo a autoridade, era constituída de 249 indivíduos, ao passo que os alemães totalizavam apenas 102 pessoas. Se a preponderância dos brasileiros em Rio Negro não diminuiu a importância colonizadora do barão de Antonina, porque a predominância deles na colônia Thereza diminuiria a do dr. Faivre? Para o presidente da província, a colônia Thereza, embora praticamente despovoada dos estrangeiros originalmente introduzidos, merecia a proteção do governo para continuar existindo com os colonos nacionais que ali haviam se fixado.

Em 1858, quando Faivre faleceu, a colônia que idealizara e construíra contava com 200 colonos. Destes, somente 22 eram estrangeiros (PARANÁ, 1858, p. 27). Ainda que entre os 178

\footnotetext{
${ }^{9}$ As relações entre Faivre e a Imperatriz eram estreitas e haviam se constituído desde que ele a atendera como médico, quando atuou profissionalmente no Rio de Janeiro. FERNANDES, 2006, p. 24-25, 59).
} 
brasileiros pudessem estar contabilizados filhos de estrangeiros nascidos no Brasil, o que os registros das autoridades informam é a predominância da população autóctone no núcleo colonial. Este dado, antes de significar o "fracasso" do projeto de Faivre, denota a importância dos chamados "nacionais" para o sucesso do empreendimento. As próprias autoridades provinciais cada vez mais passavam a considerar a adequação da população local para levar adiante os projetos coloniais. Ainda mais porque dois outros núcleos coloniais fundados na província do Paraná - Superagui e Assungui - evidenciaram, de forma semelhante ao que ocorrera na colônia Thereza, a importância da presença da população local.

A colônia de Superagui foi fundada em 1852, na península do mesmo nome, por Carlos Perret Gentil, Jorge Carlos Melly e Augusto Perret Gentil. A intenção inicialmente era povoar a região da baia de Paranaguá com imigrantes suíços. Anos depois da fundação do núcleo, em 1859, o presidente da província dizia a respeito:

o número dos [seus] habitantes no começo da colônia, em 1852, era de 22 indivíduos, em 1854 de 35, em 1855 de 64, chegou no de 1856 a 403, elevou-se no de 1857 a 450, e presentemente é de 496; sendo brasileiros 436, que constituem 89 famílias; e 60 estrangeiros, que constituem 15: ao todo, 104 fogos. (PARANÁ, 1859, p. 20). ${ }^{10}$.

A predominância de colonos brasileiros ocorreu também no núcleo de Assungui, criado por iniciativa do governo imperial, para receber imigrantes de diversas nacionalidades. Iniciada em 1860 com a fixação de 10 famílias alemãs, o afluxo de brasileiros seria cada vez maior nos anos subsequentes. Já em 1861, em resposta a uma solicitação do presidente da província, o Ministério dos Negócios da Agricultura, Comércio e Obras Públicas considerou "a conveniência de vender-se terrenos no Assungui a muitas famílias pobres [brasileiras] que ali desejam estabelecer-se" e autorizou o governo provincial vender a eles lotes que estivessem disponíveis, "concedendo-se-lhes os mesmos favores de que tem gozado os estrangeiros" (DEAP. Ofício do Ministério dos Negócios da Agricultura, Comércio e Obras Públicas de 3 de junho de 1861).

O ofício expedido pelo ministério não contrariava a legislação vigente. Tanto a Lei n. 601 de 1850 - a Lei de Terras - como o seu regulamento, de 1854, contemplavam a possibilidade de 0 governo destinar terras devolutas para colônias de nacionais. A Lei 601 de 18 de setembro de 1850 estabelecia no caput que as terras de domínio público (devolutas) deviam ser medidas e demarcadas e autorizava o governo a nelas estabelecer colônias de nacionais e estrangeiros.

\footnotetext{
${ }^{10}$ As informações sobre Superagui nos relatórios dos presidentes de província e mesmo na documentação administrativa da província não são muito fartas. As relações de Perret Gentil com o governo não eram muito estreitas, pois ele levou adiante seu empreendimento sem contar com auxílio financeiro do governo, embora o tenha demandado em algumas ocasiões. Como não tinha dívida para com o governo, não precisava a ele prestar contas do andamento de sua colônia. Cf. Dysarz (2013).
} 
(BRASIL, 1850, p. 307). O Decreto 1318 de 30 de janeiro de 1854, no artigo 3ํㅡㄹ parágrafo $7^{\circ}$ dispunha que era atribuição da Repartição Geral de Terras Públicas "promover a colonização nacional, e estrangeira" (BRASIL, 1854, p. 11). Em 1867, o governo expediu Regulamento para as Colônias do Estado, que não explicitava distinção alguma entre colonos nacionais e estrangeiros (BRASIL, 1867, p. 31).

A autorização expedida parece ter sido efetiva. Em 1868 o presidente da província relatava que a colônia, "a princípio destinada a estrangeiros, tornou-se mista por força do aviso do ministério da agricultura de 6 de julho [sic] de 1861 que mandou admitir nacionais, concedendo-Ihes os mesmos favores que aqueles [têm recebido]" (PARANÁ, 1868, p. 35). Ainda que Assungui não tivesse sido planejada para ser uma colônia de nacionais (PARANA, 1859, p. 18-22), a demanda destes fez com que a situação de fato se definisse. Já ao longo da década de 1860 ela passou a ser uma colônia mista, com predominância de brasileiros. Em 1864, os dados relatados pela autoridade administrativa da província já indicava esta situação:

Contem a colônia atualmente 45 fogos, com 197 habitantes; 50 alemães, 3 suíços, 1 francês e 143 brasileiros. São livres 186 e escravos 11. Dos livres são 99 do sexo masculino e 87 do feminino; dos escravos são 3 do sexo masculino e 8 do feminino. São casados 71, solteiros 123 e viúvos 3; os 11 escravos são solteiros (PARANA, 1864, p. 16).

O relato concluía: "a população estrangeira é pequena; a nacional vai afluindo e tomando prazos urbanos e suburbanos" (PARANÁ, 1864, p. 30).

A concretude das experiências nos núcleos coloniais parecia obrigar as autoridades a reverem suas crenças sobre as vantagens de se promover a colonização por meio da imigração. Embora ainda predominasse a ideia de que os imigrantes - especificamente os de origem europeia fossem os mais capazes para realizar a colonização, incrementando e modernizando a produção agrícola $^{11}$, sobre eles também se expressava a opinião de que eram despreparados para a obra colonizadora. Sobre os franceses que introduzira na colônia Thereza, o dr. Faivre considerou:

Eles me têm dito injúrias, que eu os tinha enganado... e todos, fora meia dúzia, tem abandonado a colônia, espalhando-se pela Província... É assim que fui malogrado nas minhas esperanças de servir aquela gente, e o Brasil,

\footnotetext{
${ }^{11}$ Como indica Pereira, reiterava-se a ideia de que os imigrantes seriam morigerados e laboriosos. Os imigrantes, morigerados, compartilhariam do ideário da positividade do trabalho e da acumulação; saberiam se portar dentro de determinadas regras de etiqueta consideradas civilizadas (PEREIRA, 1996, p. 12)
} 
levando nestes outros a indústria europeia e talvez um princípio de civilização entre os selvagens que desejava encontrar. (DEAP. Correspondência do Dr. Faivre ao Presidente da Província do Paraná, 1858. BRPRAPPR PB001 CD014.72).

A decepção que Faivre expressara em seu desabafo foi muitas vezes compartilhada por autoridades provinciais envolvidas na definição de políticas de colonização. Os colonos alemães em Assungui, considerou um Presidente de Província em 1857, eram

completamente estranhos aos trabalhos na lavoura, que demandam 0 emprego da foice e do machado; vivem exclusivamente dos recursos que tiram, quando ocupados em serviço do governo. É por esse motivo que eles abandonam a colônia, procurando a capital, onde com facilidade encontram trabalhos que Ihes são peculiares, e que nem sempre deparam naquele estabelecimento. Esta circunstância é a que com mais força concorre contra a prosperidade da colônia, a qual estaria em estado florescente, se o pessoal que nela se dedica à agricultura fosse composto unicamente de nacionais, os quais, pelo hábito em que estão, possuem a indispensável prática dos serviços das matas. (PARANÁ, 1867).

É evidente que a autoridade provincial, ao expressar estas opiniões, não levava em conta que as condições para fixação dos imigrantes na colônia eram extremamente precárias. Em relação a Assungui, esta precariedade já foi consistentemente demonstrada por historiadores que se dedicaram ao estudo da colônia (LAMB, 1994; PEREIRA, 1997, p.1-15; PEREIRA, 1996; NISHIKAWA, 2007). A difícil situação dos imigrantes ingleses na colônia levou o governo britânico a enviar uma missão de fiscalização ao local, que foi realizada pelo cônsul Lennon Hunt, em 1874. (BRASIL, 1875; HUNT, 1998). O que quero destacar aqui, entretanto, é que a implementação dos núcleos coloniais dos anos 1840-1870 obrigou as autoridades provinciais a olharem para as populações locais e a relativizarem a ideia de que colonização só poderia ser efetivada por estrangeiros. Já em 1854, sabendo do êxodo dos colonos franceses da colônia Thereza, o presidente da província - Gois e Vansconcelos - ressaltou a importância dos brasileiros naquele núcleo, cuja situação parecia demonstrar que era "um contracenso despender dinheiro e esforços em mandar vir de países remotos colonos para cultivar nossas terras devolutas, deixando entregues ao ócio e a miséria não poucos brasileiros" (PARANÁ, 1854, p. 69). Estes, segundo Faivre eram "muito mais próprios para trabalhar e viver nos sertões do que os estrangeiros" (DEAP. Correspondência, s.d.). 
Em 1876 - quando estava já em curso o projeto de colonização de Lamenha Lins, centrado na figura do imigrante e na sua alocação em núcleos coloniais nas áreas circundantes à capital da província (BALHANA, MACHADO E WESTPHALEN, 1969, p. 168) - um artigo publicado no jornal Província do Paraná, demonstra que as percepções negativas sobre a população local não eram unívocas e que o debate em torno do lugar que deveriam ocupar nas políticas pública não estava restrito aos gabinetes dos presidentes, aos círculos das autoridades governamentais ou mesmo de empreendedores da colonização. Nele, o jornalista dizia da necessidade de se construir uma estrada que pudesse possibilitar o escoamento da produção de Assungui, e, portanto, viabilizar a colonização da região. Ele então argumentava:

\footnotetext{
Pela palavra colonizar geralmente entende-se o povoamento do país por estrangeiros. Não foi nessa estrita acepção que a empregamos no princípio deste tosco escrito. O termo colono não significa só novo povoador, mas também agricultor. Reunir nacionais dispersos, constituindo em centros de atividade e trabalho; dar-lhes estradas que facilitem suas permutas; elevá-los a seus próprios olhos na escala social e moral; também é colonizar, também é promover o desenvolvimento da população do país. Não é isto uma quimera que inventamos: é um fato afirmado pela ciência fisiológica, pela economia e comprovado pela estatística (A Província do Paraná, 9 de janeiro de 1876).
}

Além de considerar que colonização não fosse um termo necessariamente associado com imigração, este jornalista talvez estivesse expondo as motivações das populações locais para se fixarem nas colônias e nelas se tornarem proprietários. Eram locais, afinal, para onde o poder público voltava sua atenção, dos quais os jornais falavam.

\section{Considerações finais}

Ainda que a produção historiográfica sobre a colonização e sobre a imigração no Paraná tenha sido profícua e tenha se destacado pela sua qualidade, o tema, a mim parece, está longe de esgotar-se.

Ao longo deste artigo, a partir de leituras e de pesquisas empíricas que venho compartilhando com estudantes e jovens pesquisadores nos últimos anos, procurei sugerir duas possibilidades de 
problematizar o tema. A primeira delas considera que políticas públicas voltadas à promoção da imigração no início da organização institucional da província tinham em vista disponibilizar mão de obra para produtores constituídos ou para as obras públicas que, como se considerava, eram urgentes e necessárias para desenvolver a nova unidade político-administrativa, criada em 1853. Assim, pesquisas que possam detalhar as experiências de estrangeiros introduzidos na região nas décadas de 1850 e 1860 podem evidenciar uma história da imigração diferente daquela até então demonstrada pelos estudos que se dedicaram ao período posterior - após 1870 e sobretudo após 1890 -, quando passaram a predominar núcleos de fixação de estrangeiros em pequenas propriedades agrícolas.

A outra possibilidade que o artigo sugere é o questionamento da sinonímia entre imigração e colonização. Se considerarmos os registros das experiências realizadas nos anos 1850 e 1860 cuja aproximação foi feita aqui especialmente por meio dos relatos dos presidentes da província verificamos a importância que teve a população local para viabilizar os núcleos coloniais constituídos naquele período, fosse por particulares, fosse pelo poder público. Pesquisas que se animem a explorar a participação dos "nacionais" no processo de colonização da província permitirão caracterizar a origem social desta população, a motivação para ocupar os lotes demarcados nos núcleos, a relação que estabeleceram com os estrangeiros. Podem permitir também relativizar a existência do tão propalado "vazio demográfico" com que se dizia caracterizar a região. Tal caracterização, mais que um dado de realidade, poderia se configurar como argumento político correlato àquele que, na região cafeeira, se constituiu em torno da "carência de braços" para as lides agrícolas. O "vazio demográfico" serviria para desqualificar a população local - cabocla, mestiça, com ascendência indígena e africana -, porque considerada incapaz de promover uma ocupação compatível com o progresso idealizado, para o qual os estrangeiros estariam mais bem preparados. De forma correlata, na região cafeeira, considerando-se a incapacidade do trabalhador nacional - ex-escravo na maioria -, se diagnosticou a inexistência de trabalhadores em número suficiente para prover as necessidades da produção agrícola. ${ }^{12}$.

A pesquisa focada neste período inicial das experiências de colonização e imigração também possibilitaria compreender rupturas no processo, provocadas não só por autoridades públicas envolvidas, mas também, certamente, pelas ações e iniciativas de imigrantes, brasileiros, colonos, trabalhadores.

\footnotetext{
${ }^{12}$ A ideia de vazio demográfico é questionada em Moreira (2000, p. 18). A produção que problematiza a "carência de braços" na região cafeeira é extensa. Entre tantos outros: Eisenberg (1989), Naxara (1999), Lamounier (2010).
} 


\section{Referências}

ANDREAZZA, Maria Luiza. O Paraíso das Delícias: um estudo da imigração ucraniana -18951995. Curitiba. Aos Quatro Ventos, 1999.

BALHANA, Altina Pilati. Um Mazzolino de Fiori. Curitiba: Imprensa Oficial; Secretaria de Estado da Ciência, Tecnologia e Ensino Superior, 2002.

BALHANA, Altiva Pilati; MACHADO, Brasil Pinheiro; WeStPhALEN, Cecília Maria. História do Paraná. Curitiba: Grafipar, 1969.

BEGA, Maria Tarcisa. S. Letras e política na Paraná: simbolistas e anticlericais na República Velha. Curitiba: Editora da UFPR, 2013.

BORGES, Luiz Adriano. Senhor de homens, de terras e de animais. A trajetória política e econômica de João da Silva Machado - Província de São Paulo, 1800-1853. 2014. Tese (Doutorado em História) - Universidade Federal do Paraná, Curitiba, 2014.

BOSCHILIA, Roseli (Org.). Reconstruindo memórias: os poloneses do Santo Inácio. Curitiba: Universidade Tuíuti do Paraná, 2004.

BRASIL. Coleção das Leis do Império do Brasil - Atos do Poder Legislativo. Rio de Janeiro: Tipografia Nacional, 1850. T. XI, pte I.

BRASIL. Coleção das Leis do Império do Brasil - Atos do Poder Executivo. Rio de Janeiro: Tipografia Nacional, 1854. T. VII, pte II.

BRASIL. Coleção das Leis do Império. Atos do Poder Executivo. Rio de Janeiro: Tipografia Nacional, 1861. v. I, pte II.

BRASIL. Colecção das Leis do Brazil de 1808. Rio de Janeiro: Imprensa Nacional, 1891. Disponível em:<http://www.planalto.gov.br/ccivil_03/revista/Rev_48/dim251808.htm>. Acesso em: 12 já. 2014.

BRASIL. Relatório do Inspetor da Tesouraria da Fazenda, Lucas Antonio Monteiro de Barros, feito por ordem do presidente da província. In: Relatório apresentado á Assembleia Legislativa da Província do Paraná pelo $1^{0}$ vice-presidente, Sebastião Gonçalves da Silva, na abertura da 1.a sessão da 6.a legislatura em 21 de fevereiro de 1864. Curitiba: Tip. de Candido Martins Lopes, 1864.

BRASIL. Relatório sobre a colônia de Assunguy apresentado a ambas as Casas do Parlamento por Ordem de Sua Majestade, 1875. Monumenta, Curitiba, v. 1, n. 1, pp. 19-132. 
COSTA, Emilia Viotti da. Da Monarquia à República: Momentos Decisivos. 6. ed. São Paulo: Ed. da UNESP, 1989.

DEAP. Departamento de Arquivo Público do Paraná. Correspondência do Dr. Faivre ao Presidente da Província do Paraná, 1858. BRPRAPPR PB001 CD014.72.

DEAP. Departamento de Arquivo Público do Paraná. Ofício do Ministério dos Negócios da Agricultura, Comércio e Obras Públicas, de 3 de junho de 1861.

DYSARZ, Caiubi Martins. Os suiços de Superagui. Colonização e imigração no Paraná do século XIX. 2013. Dissertação (Mestrado em História) - Universidade Federal do Paraná, Curitiba, 2013.

DYSARZ, Caiubi Martins. Colônias de estrangeiros ocupadas por brasileiros: Paraná (1847-1876). V CONGRESSO INTERNACIONAL DE HISTÓRIA, 5., 2011, Maringa. Disponivel em:<http://www.pph.uem.br/novo/index.php?id=10\&pid=22>. Acesso em: 17 nov. 2014.

EISENBERG, Peter. O homem esquecido: o trabalhador livre nacional no século XIX: sugestões para uma pesquisa. In: Homens esquecidos. Campinas: Ed. da Unicamp, 1989.

FERNANDES, Josué Corrêa. Saga da esperança do socialismo utópico à beira do Ivaí. Curitiba: Imprensa Oficial, 2006.

GOULART FILHO, Alcides. A estrada da mata e a integração regional pelo interior do Brasil Meridional. 2012. Disponível em:<http://www.apec.unesc.net/VI_EEC/ sessoes_tematicas/Tema4Historia\%20Economica/Artigo-6-Autoria.pdf>. Acesso em: 15 dez. 2014.

HUNT, G. Lennon. Imigração para o Brasil. Relatório sobre a colônia de Assunguy apresentado a ambas as Casas do Parlamento por ordem de Sua Majestade em 1875. Monumenta, Curitiba, v. 1, n. 1, 1998.

IOTTI, Luiza Horn. Imigração e Colonização. Tribunal de Justiça do Rio Grande do Sul, 2003. p. 23-4 disponível em:<https://www.tjrs.jus.br/export/poder_judiciario/historia/ memorial_do_poder_judiciario/memorial_judiciario_gaucho/revista_justica_e_historia/issn_16765834/v3n5/doc/07-Luiza_lotti.pdf>. Acesso em: 10 set. 2014.

LAMB, Roberto Edgar. Uma jornada civilizadora: Imigração, Conflito Social e Segurança Pública na Província do Paraná - 1867 a 1882. Curitiba, 1994.

LAMOUNIER, Maria Lucia. Entre a escravidão e o trabalho livre. Escravos e imigrantes nas obras de construção de ferrovias no Brasil no século XIX. Economia (Campinas), v. 9, p. 215-245, 2010.

LAZARI, Maria Beatriz. Imigração e Ideologia. Reação do Parlamento brasileiro à política de imigração e colonização - 1850-1875. Porto Alegre: Escola Superior de Teologia São Lourenço de Brindes; Caxias do Sul: Universidade de Caxias do Sul, 1980. 
LEANDRO, José Augusto. Dicionário Histórico e Geográfico dos Campos Gerais. 1996. Disponível em:<http://www.uepg.br/dicion/verbetes/a-m/candido_abreu.htm>. Acesso em 10 nov. 2014.

MACHADO, Brasil Pinheiro, et al. Campos Gerais - estruturas agrárias. Departamento de História da Universidade Federal do Paraná: Curitiba, 1968.

MACHADO, Paulo Pinheiro. A política de colonização do Império. Porto Alegre: Editora da Universidade do Rio Grande do Sul, 1999.

MARTINS, Romário. História do Paraná. Curitiba: Travessa dos Editores, 1995.

MARTINS, Romário. Quantos somos, quem somos. Dados para a história e a estatística do povoamento do Paraná. Curitiba: Empresa Gráfica Paranaense, 1941.

MARTINS, Wilson. Um Brasil diferente. Ensaio sobre fenômenos de aculturação no Paraná. 2. ed. São Paulo: T. A. Queiroz, 1989.

MOREIRA, Vânia Maria Losada. Vazios demográficos ou territórios indígenas. III Encontro Regional de História. Vitória, ES: ANPUH/ES - Associação Nacional de História/Regional do Espírito Santo, 2000. Disponível em:<http://www.angelfire.com/planet/anpuhes/ ensaio30.htm\#_ftn1>. Acesso em: 24 nov. 2014.

NADALIN, Sérgio Odilon. Imigrantes de origem germânica no Brasil: ciclos matrimoniais e etnicidade. Curitiba: Aos Quatro Ventos, 2000.

NAXARA, Márcia. Estrangeiro em sua própria terra - representações do brasileiro (1870-1920). São Paulo: Annablume, 1999.

NICOCELI, Vanessa. Hermann Blumenau: uma experiência de colonização em Santa Catarina (18461884). 2014. Dissertação (Mestrado em História) - Universidade Federal do Paraná, 2014.

NISHIKAWA, Reinaldo Benedito. Terras e imigrantes na colônia Assunguy. Paraná, 1854-1874. Dissertação de Mestrado, Universidade de São Paulo, 2007. Disponível em <http://www.uepg.br/dicion/verbetes/a-m/candido_abreu.htm>. Acesso em: 10 nov. 2014.

OLIVEIRA, Márcio de. Por uma sociologia do Brasil Meridional. IN OLIVEIRA, Márcio e ZWAKO, José Eduardo Leon. Ensaios de Sociologia e História Intelectual do Paraná. Curitiba: Editora da UFPR, 2009, pp. 17-29.

PARANÁ. Deliberações do Governo da Província do Paraná. 1855. Curitiba: Tipografia Paranaense, 1912. Tomo III.

PARANÁ. Leis, Decretos, Regulamentos e Deliberações do Governo da Província do Paraná. 1856a. 1912. Tomo II. 
PARANÁ. Relatório do presidente da província do Paraná, o conselheiro Zacarias de Góes e Vasconcellos, na abertura da Assembleia Legislativa Provincial em 15 de julho de 1854. Curitiba, Tip. Paranaense de Candido Martins Lopes, 1854.

PARANÁ. Relatório da Província do Paraná - o Conselheiro Zacarias de Goes e Vasconcellos na Abertura da Assembleia Legislativa Provincial. 1855. Curitiba: Tipografia Paranaense de C. Martins Lopes, 1855.

PARANÁ. Relatório apresentado à Assembleia Legislativa Provincial do Paraná pelo Vice-Presidente em Exercício Henrique de Beaurepaire Rohan - 1856. Curitiba: Tipografia Paranaense de C. Martins Lopes, 1856b.

PARANÁ. Relatório do Estado da Província do Paraná - apresentado ao Vice-Presidente José Antonio Vaz de Carvalhaes pelo Presidente Vicente Pires da Mota por ocasião de Ihe entregar a administração da mesma província, Curitiba: Tipografia Paranaense, 1856c.

PARANÁ. Relatório apresentado ao Excelentíssimo senhor doutor Francisco Liberato de Matos Muito digno Presidente da Província do Paraná pelos $2^{\text {}}$ Vice-Presidente José Antonio Vaz de Carvalhaes sobre o estado da administração d mesma Província no ano de 1857. Curitiba: Tipografia Paranaense de C. Martins Lopes, 1858a.

PARANÁ. Relatório do presidente da província do Paraná, Francisco Liberato de Mattos, na abertura da Assembleia Legislativa Provincial em 7 de janeiro de 1858. Curitiba: Tip. Paranaense de C. Martins Lopes, 1858b.

PARANÁ. Relatório do presidente da província do Paraná, Francisco Liberato de Mattos, na abertura da Assembleia Legislativa Provincial em 7 de janeiro de 1859, Curitiba: Tip. Paranaense de Candido Martins Lopes, 1859.

PARANÁ. Relatório apresentado á Assembleia Legislativa da Província do Paraná pelo 1.0 vicepresidente, Sebastião Gonçalves da Silva, na abertura da 1.a sessão da 6.a legislatura em 21 de fevereiro de 1864. Curitiba: Tip. de Candido Martins Lopes, 1864.

PARANÁ. Relatório do Presidente de Província do Paraná, Presidente Polidoro Cezar Burlamaque na Assembleia provincial em 15 de Março de 1867. Curitiba: Typ. Paranaense, 1867.

PARANÁ. Relatório apresentado a Assembleia Legislativa da província do Paraná na abertura da 1.a sessão da 8.a legislatura pelo presidente, bacharel José Feliciano Horta de Araujo, no dia 15 de fevereiro de 1868. Curityba: Typ. de C. Martins Lopes, 1868.

PEREIRA, Luiz Fernando Lopes. Paranismo: o Paraná inventado: cultura e imaginário no Paraná da Primeira República. Curitiba: Aos Quatro Ventos, 1997. 
PEREIRA, Magnus Roberto de Mello. Semeando iras rumo ao progresso. Curitiba: Ed. UFPR, 1996..

PEREIRA, Magnus. Tess não veio a Curitiba. Monumenta. Curitiba, v. 1, n. 1, p. 1-15, 1998.

PETRONE, Maria Teresa. O imigrante e a pequena propriedade. São Paulo: Brasiliense, 1982.

PROVINCIA DO PARANÁ, A. 9 de janeiro de 1876. Typ. da Viuva Lopes, 1876.

UNIVERSIDADE FEDERAL DO PARANÁ. Ata da Reunião do Departamento de História da Faculdade de Filosofia em 2 de dezembro de 1964. História: Questões \& Debates, Curitiba, n. 50, p. 285-315, p. 285-315, jan./jun. 2009.

WACHOWICZ, Ruy. Tomás Coelho: uma comunidade camponesa. Curitiba: Real Artes Gráficas Ltda., 1977.

WACHOWICZ, Ruy. Abranches: paróquia de imigração polonesa. Um estudo de História Demográfica. Dissertação (Mestrado) - Curitiba: Universidade Federal do Paraná, 1974.

SANTOS, Carlos Roberto Antunes dos. História da Alimentação no Paraná. Curitiba: Fundação Cultural de Curitiba, 1995.

ZWAKO, José Eduardo Leon. O Paraná das etnias: ensaio sobre racismo na produção intelectual de Bento Munhoz da Rocha Neto". In: OLIVEIRA, Márcio; ZWAKO, José Eduardo Leon. Ensaios de Sociologia e História Intelectual do Paraná. Curitiba: Editora da UFPR, 2009. p.45-57.

Recebido em 08.01.2015 - aprovado em 15.11.2015 